\title{
THE NEURODEVELOPMENTAL ASSESSMENT OF THE HIGH RISK INFANT
}

\section{Magasiner, C Molteno*}

\section{SUMMARY}

This article describes how postural tone, postural reactions and basic reflexes can be used to evaluate the neurodevelopmental status of the infant. It includes a simple assessment which can be used in a practical setting.

\section{INTRODUCTION}

Many infants who would formerly have died now survive thanks to improvements in neonatal intensive care. Over the past three years, a number of these survivors have been successfully assessed at the Groote Schuur High Risk Follow-up Clinic, using the infant-neurodevelopmental assessment outlined in this paper.

The majority of infants seen fall into two main groups: very low birth weight (VLBW) infants; and full term infants who have presented with clinical signs of hypoxic-ischaemic encephalopathy.

VLBW infants (below 1500 grams) are at risk for long-term neurodevelopmental handicap because the immature brain has been exposed to potentially damaging insults both before and after delivery. In these neonates there is increased incidence of asphyxia neonatorum, hyaline membrane disease and anoxic spells due to an immature respiratory centre. Resultant hypoxia may lead to periventricular leucomalacia and intraventricular haemorrhage (IVH), Approximately $45 \%$ VLBW infants demonstrate IVH. Many of these haemorrhages are small and do not cause clinical problems. About $10 \%$ of VLBW infants develop neurodevelopmental problems. In full term infants, hypoxic ischaemic encephalopathy may lead to neuronal damage.

It is therefore imperative that neurodevelopmental assessment form part of the long-term follow up of these infants as early diagnosis and treatment can lead to improved long-term outcome.

The aim of the initial neurodevelopmental assessment is to categorize infants into three groups:

1. Normal: In Cape Town these infants are followed up by paediatricians at Midwife Obstetric Units situated in the community.

2. Some abnormal signs but no serious abnormalities: These infants are seen again at our High Risk Clinics at six, nine and 12 months chronological age.

3. Definite neurological impairment: These infants are referred to the Cerebral Palsy Clinic at Red Cross War Memorial Children's Hospital.

The first assessment is not strongly predictive but gross abnormality can be identified and abnormal signs followed up.

\section{METHODS AND OBSERVATIONS}

Full term infants ( 37 to 42 weeks) are first assessed neurodevelopmentally at 4.5 months chronological age. VLBW infants are first assessed neurodevelopmentally at 4.5 months corrected age (ie 40 weeks post conception plus 18 weeks). This is a good age at which

\section{OPSOMMING}

Hierdie artikel beskryf hoe posturale tonus, posturale reaksies en basiese reflekse gebruik kan word om die neurologiese vlak van ontwikkeling van die kind te evalueer. Dit sluit in 'n eenvoudige evaluering wat in die praktyk gebruik kan word.

to begin assessing VLBW infants as most of the preterm movement patterns associated with low tone should nolonger be present, eg head lag, lack of trunk control, increased range of movement and extension in the legs. Therefore both groups of infants should exhibit the same movement patterns at the time of neurodevelopmental assessment.

The assessment follows a definite sequence from gentle to more vigorous movement. This reduces the likelihood of crying which leads to increased tone. There are two stages to the assessment:

In the first stage, the infant is assessed fully dressed while sitting sideways on the mother's lap.

- A bangle is held in front of the infant's face to assess ability to focus the eyes.

- The bangle is positioned within the infant's grasp to test midline hand function and symmetry.

- The bangle is then moved to each side to assess eye following.

- A rattle is shaken behind each ear to test for awareness of sound.

In the second stage the infant is undressed and the assessment follows the routine illustrated in the Figure.

1. Supine lie: The infant's posture is assessed in the supine position. The examiner looks to see whether:

- the head is in the midline

- the hands are brought to the mouth

- the infant kicks his legs reciprocally

- the infant is alert and responsive and whether he smiles and babbles.

The mother can verify each of these items if necessary.

In the Figure, "Head asymm" (head asymmetrical) means the infant lies with his head turned to one side. "Head symm" (head symmetrical) means the infant lies with his head in the midline.

Sometimes lack of hand function on one side is associated with the absence of leg kicking on the same side.

Use of only one hand in an infant under one year needs to be referred for further assessment. Dominance begins gradually between $12-18$ months.

The "Angles" method (according to Ellison ${ }^{1}$ ) tests tone in legs and arms by moving the limbs through a range of movement in a set pattern. Often the expected normal limit of range can be reached but quality of movement as the limb is moved through the range is also important.

Does the movement feel stiff or floppy?

No infant should have a smaller range of movement than indicated on the chart. All movements are performed smoothly.

2. Adductor angle: Examiner opens legs as far as possible. The angle

* V Magasiner, Dip Phys (UCT)

C Molteno, MD, PhD, FCP (SA)

Cerebral Palsy Clinic, Red Cross War Memorial Children's Hospital, Rondebosch, Cape Town

First published in the May/June 1990 issue of PEDMED, the South African Paediatric Medicine Journal, on page 23. PEDMED is

published by the Medical Division of George Warman Publications (Pty) Ltd P O Box 704, Cape Town 8000 
formed by the legs is measured.

3. Head to ears: Buttocks on the table. The legs are kept straight and moved towards the ears. When there is resistance to this movement, the angle formed from table surface to legs is measured.

4. Popliteal angle: Buttocks on the table. The hips are flexed to bring the knees to either side of the abdomen, until there is resistance. Then knees are extended. When there is resistance to this movement, the angle formed between the lower and upper leg is measured.

5. Dorsiflexion angle of the foot: The knee is extended. The foot is dorsiflexed and the angle between foot and leg is measured.

6. Scarf sign: The examiner takes infant's hand and pulls arm across the infant's chest until there is resistance. The position of the elbow is noted in relation to the midline. The scarf sign tests the movement of the scapula around the chest wall.

7. With the infant in supine position, traction is applied to arms until trunk forms an angle of 45 degrees with the examination plane. Grasp at wrist level. DO NOT insert finger into palm as this initiates total flexion of head and trunk ${ }^{2}$.

- Complete head lag with extended arms.

- Moderate head lag

- Head is in line with the trunk, the arms and legs are in flexion with feet elevated.

- The child actively flexes the head forward with strong elbow flexion. Knees go from flexion to extension.

Sometimes the infant comes up to the sitting position with the spine slightly extended. This is normal. However, if the infant pushes back actively into extension as the examiner pulls to sit, careful follow-up is indicated.

8. Sitting:

- Complete flexion of trunk.

- Extension down to thoracic spine.

- Extension down to lumbar three.

- Prop sitting. Weight-bearing forward onto hands.

- Extension with cervical lordosis.

- Extension with cervical and lumbar lordosis.

- Infant is able to rotate his trunk sideways.

9. Prone lie:

- Elbow flexion support.

- Elbow extension support.

10. Landau:

- Infant held in prone position with trunk supported.

- Head flexed, trunk curved.

- Head, cervical and thoracic regions form one horizontal plane.

- Extension of head above horizontal plane. Full extension of trunk and pelvis.

11. Axillary hanging: Examiner holds infant from behind just below axillae with feet free of table.

- No head control with legs in loose flexion.

- Legs in strong flexion.

- Preparation for weight bearing with extended legs.

Watch for abnormal scissors pattern of legs, that is legs crossed with plantarflexed feet. An infant who hyperextends the spine during this test should be followed up carefully.

12. Votja side tilting: Infant is held vertically at chest level with back to examiner and then tilted into lateral horizontal position.

- Moderate trunk flexion. Moro-like response in upper arm. Upper leg should flex with underlying leg extending.

- Head and trunk righting, flexion of upper arm, flexion of both legs.

13. Collis horizontal: Infant lies on his side close to examiner with back to examiner. The examiner's hands grasp over shoulder and hip joints to prevent stretching ligaments.

Raise infant just off table.

- Flexion of lower leg and arm.

- Lower arm elbow extended with hand partially open touching table.

- Elbow extended, palm supports body weight.

- Lower arm and leg down on table.

Watch for abnormal stiff extension of the lower leg. Lack of weight-bearing in the lower arm as an isolated clinical finding is often found in infants who dislike prone lying.

In both the Votja and Collis Horizontal responses trunk righting must be carefully watched. The head and trunk might right themselves as the infant is tilted sideways, that is, head and trunk must not remain in side flexion on the lower side.

14. Grasp reflex: Place index finger in palm from ulnar side. Fisting should cease at 3.5 months.

15. Moro response: Infant is supported on the examiner's forearm with the head held in the examiner's hand. The head is allowed to fall back. Normally the infant's arms go out into abduction and extension followed by flexion and adduction. Sometimes the preterm infant's arms do not return to flexion and adduction.

16. Asymmetrical tonic reflex (ATNR) is observed when testing following or can be assessed by turning head. The arm and leg on the skull side should flex and on the face side extend. Sometimes this response is only present in the arm. It is not an obligatory response.

17-20. Protective extension

17. Downwards: By 4.5 months the infant is held vertically and rapidly lowered. The legs should extend with abduction and external rotation. The infant should weightbear on flat feet.

18. Sideways: By six months the infant is placed sitting and is pushed sideways on one shoulder with sufficient force to cause loss of balance. The opposite arm should abduct with extension of elbow and wrist to weightbear.

19. Forwards: By seven months the child is held vertically and tilted forwards to the table. The arms project forwards with extended elbows, wrist and fingers.

20. Backwards: By nine months the child sits and is pushed backwards. Both arms should extend backwards, although sometimes the reaction is seen only in one arm. sought.

In categorising infants into groups, clusters of signs should be

In the group "Definite neurological impairment", abnormal signs are:

- Marked head lag

- Lack of trunk.righting

- Increased tone in legs and arms with decreased range of movement

- Scissoring

- Opisthotonos

- Definite asymmetry

- Irritability

- Feeding problems

- Apathy - not fixing or following

Abnormal signs which call for further follow up include:

- The infant who pushes backwards into extension

- Moderate head lag and lack of trunk righting

- Moderate asymmetry

- Increased tone in legs with decreased range of movement

- Persistent standing on toes

These signs may disappear but must be sought at subsequent follow up.

Drillien ${ }^{3}$ and Tudehope ${ }^{4}$ call this condition "Transient Dystonia" and suggest that even though they disappear by 8-12 months, the signs may be predictive of later learning difficulties. In such cases not only is the infant re-examined but advice is also given to the mother on correct handling, for example:

- Discourage the use of walking rings and baby bouncers.

- Discourage lap bouncing with extended legs. Rather encourage sitting to standing astride the mother's leg. 
- The infant should be held at hip level when sitting on mother's lap and not around the chest wall which encourages extension backwards.

\section{REFERENCES}

1. Ellison P. Neurologic Development of the High Risk Infant. Clinical Perinatology Vol II, No 1, 1984.

2. Dubowitz L. Personal communication.

3. Drillien C. et al. Low birth weight children at early school-age; a longitudinal study. Dev Med Child Neurol 1980;22:26-47.

4. Tudehope D. Minor neurological abnormalities during the first year of life in infants of birth weight of less than 1500 grams. Aust Paediatr J 1981;17:265-268

5. Votja V. (1976): Die cerebralen Bewegungsstörungen en Säuglingsalter. Stuttgart, Enke.

6: Milani Comparetti A. Routine Developmental Examination in Normal and Retarded Children. Dev Med \& Child Neurol 1967;9:631-638.

\section{The NCR Report}

\section{...continued from page 12}

The PPA is currently drawing up guidelines for the writing of medico-legal reports. They negotiate the tariff structure annually with RAMS. They are also trying to bring about less restrictive rules relating to advertising.

Miss S Irwin-Carruthers read the report on the World Confederation for Physical Therapy. Items for the WCPT newsletter are now being submitted regularly resulting in favourable comment from several other countries. Regionalisation is proceeding and the first meeting of the Africa Region will be hosted by the Zimbabwe Physiotherapy Association.

Arising out of a joint WCPT/WHO venture on the care of the elderly, Prof J Beenhakker is investigating the needs of the elderly in South Africa and the extent to which these needs are being met by physiotherapists.

The WCPT Congress will be held at the Barbican Centre, London. The theme is "Care in Our Hands". Abstracts are due by 30 September 1990.

The report of the National Council for the Physically Disabled in South Africa was written by Mrs A Mathias and read by Mrs J A C Gilder. Mrs Mathias was re-elected to the Executive Committee of the National Council and to the Management committee of the Cerebral Palsy Division. Physiotherapists are invited to contribute articles on aspects of their work with the cerebral palsied to "The White Dove".

The Cerebral Palsy Division met in Kimberley from 5-7 March 1990. A number of workshops were held and the results discussed. What arose out of the discussions were the need for increased physiotherapy services in particular, but also the general shortage of supplementary health profession members working in the CP schools. Another lack discussed was the dearth of facilities in the Transvaal, but also generally throughout the country. Concern was also expressed at the overwhelming number of learning-disabled children at $\mathrm{CP}$ schools resulting int the transfer of $\mathrm{CP}$ children to inadequately staffed training centres.

Miss M-A van der Velde read the report of the SA Neurodevelopmental Therapy Association. The NDT Association continues to offer a variety of courses. They have 150 therapists on the waiting list for the basic course. A congress was held for 19-21 April 1990 at the Forest Town School. Concern was expressed that many Black, Coloured and Asian neurologically impaired patients have little or no access to NDT-trained therapists.

\section{Some of the Matters for Discussion:}

Natal Coastal suggested the organisation of a National Physiotherapy Week. It was decided that Back Week should not be replaced, but that an additional week be considered by the Action Committee. The formation of a special group for those interested in sports injuries was suggested. This was considered an excellent idea.

\section{THE LEPROSY MISSION}

\section{is looking for a \\ CHRISTIAN PHYSIOTHERAPIST}

* Treating leprosy sufferers

* In hospital and in community

* Home industry training

* Expect to travel

* Commence as soon as possible

Apply to : The Executive Director, Rev $L$ Wiseman

P O Box 89527, Lyndhurst 2106 Telephone (011) 882-6156

\section{CLASSIFIED ADVERTISEMENTS GEKLASSIFISEERDE ADVERTENSIES}

WORKING HOLIDAY IN THE UK AND CANADA

CONTACT: Dr Chari Loubscher at P O Box 1774, George 6530

or telephone (0441) 74-5122.

\section{JOHANNESBURG}

Physiotherapist required for private practice in pleasant working conditions. Hospital/orthopaedics.

CONTACT: Sarina Dietrich (011) 782-6813 (w), 782-5944 (h).

\section{HERMANUS}

Full time physiotherapist required for private practice in pleasant working conditions.

CONTACT: Lorna Sutcliffe (0283) 22735 (w) 23675 (h).

\section{EQUIPMENT FOR SALE}

LTU 904 Laserex laser therapy unit for sale. Hardly used.

CONTACT: A Lewis (03231) 51806 (pm only).

APPARAAT TE KOOP

Carters Rosslyn traction couch. Baje goeie toestand - feitlik nuut.

$R 2,000$ of NKA.

KONTAK (024) 53-4245.

\section{PRETORIA}

Oostelike voorstede. Voldag of halfdag fisioterapeut benodig in privaat praktyk. Manipulatiewe opleiding belangrik. Ure en salaris onderhandelbaar.

KONTAK : Hannelie Nel (012) 45-1367 (w) of (012) 345-1575 (h).

\section{BEDFORDVIEW}

Physiotherapist required to join busy practice. Knowledge of sports injuries and Maitland concept would be useful.

CONTACT: Sue (011) 615-6205 (w) or (011) 615-1137 (h).

The rewording of Rule 21 was further discussed. A motivation by the PPA would be sent to the Professional Board.

From Northern Transvaal came a number of suggestions for the future administrative needs of the Society. The process of centralisation has already been started. Annual subscriptions will be paid directly to head office which has also computerized the full membership. The feasibility of compiling a data base of research, statistics and speakers for lectures were discussed.

The possibility of holding a Council Meeting every year with fewer NEC meetings was presented. The major objection was that by limiting the number of delegates, the exchange of ideas might be affected.

Western Province tabled their Community Physiotherapy statement and requested more input. 